\title{
The Symbolic/Culture Approach: Managing Transition in the Service Industry
}

\author{
Judi Brownell
}

Cornell University

\begin{abstract}
Hospitality managers face many challenges as they implement strategic plans and lend their organizations through the transition process. In this paper, organizational transition is viewed from a symbolic/culture perspective and the impact of organizational culture on the change process is explored. The change process is seen as a disruption of existing organizational values, beliefs, and assumptions. Communication strategies are viewed as essential for effective transition leadership, enabling hospitality managers to overcome such barriers to change as: the customer as partial employee, a diverse workforce, and high levels of uncertainty. Effective managers use strategic ambiguity as well as myths and stories to communicate new organizational values. In order to lead their organization through the transition process, managers also facilitate information sharing and serve as boundary spanners, interpreting the perceptions of one group or department to those with different perspectives and concerns. Finally, hospitality leaders model effective listening skills which are essential to wise decision-making and the development of supportive work environments. The hospitality industry can respond to on-going organizational change by helping its managers understand the nature of organizational culture and develop the communication competencies that facilitate the transition process.
\end{abstract}

Keywords: organizational communication, organizational culture, organizational transition, communication strategies, symbolic/culture approach 


\section{The Symbolic/Culture Approach: Managing Transition in the Service Industry}

\section{Introduction}

The internationalization of the hospitality workforce and rapid changes in customer demands have made the need for effective managerial communication skills ever more pressing. As the workplace becomes increasingly automated, clear and timely communication becomes vital; as the workforce becomes more diverse, the need to understand and respond appropriately to the human dimension becomes management's key task (Young and Smith, 1988). This rapid and continuous transformation process places new and complex demands on hospitality leaders.

Changes in the manager's role necessitate a shift in the attitudes and competencies required for effective management. No longer are the highly rational, mechanical models of the past appropriate. No longer is management a simple matter of working hard at routine tasks to 'get the job done'. New paradigms and approaches have been developed and applied that take into account the dynamic nature of service organizations and the people responsible for their functioning.

One recent approach to understanding how organizations operate-and how the communication strategies that leaders apply facilitate organizational change-is called the symbolic/culture perspective. This approach appears, after a decade of critical review (Smircich. 1983; Wiio. 19SS), as one of the most useful perspectives for viewing the human aspects of organizational transitions. As Bridges (19S5) clarifies, transitions require organizational members to go through an inner reorientation process' as they stop *doing things the way they used to and start doing them differently' (p. 28). Simply, transitions determine whether changes work. 
This paper takes a symbolic/culture perspective as it addresses the challenges hospitality managers face in implementing strategic plans and in managing the human dimensions of the transition process. First, the symbolic nature of communication is discussed as it influences the change process. The importance of values to successful organizational transition is emphasized, and strategies are suggested for creating unity within an increasingly diverse workforce. Three of the most significant barriers to planned change are presented for consideration. Finally, the key communication competencies of effective hospitality leaders are described as they contribute to managers' ability to introduce, implement, and monitor their strategic plans.

\section{Organizational culture and the symbolic nature of communication}

When change masters (Kanter, 1983)—organizational leaders_-speak of strategic

planning, they are referring to a deliberate intervention, a process usually initiated by upper level management and designed to accomplish a number of purposes. Strategic planning provides direction for the organization and helps it assert control over its destiny (Hunsaker, 1982; Hunsucker and Loos, 1989). Effective strategic plans ultimately result in changes that affect organizational members' ways of thinking, managing, and operating.

Allaire and Firsirotu (1989) suggest that the key to strategic planning lies 'not in the product but in the process. Planning becomes like jogging; it is not an efficient way to get anywhere...but if practiced regularly, it will make us feel better' (p. 8). Unfortunately, there is more than a kernel of truth to their statement; although strategic planning has become a hot topic (everyone is doing it), the results are not always apparent. If, indeed, managers work in evermore turbulent environments, where change is the rule rather than the exception, the strategic 
planning process is likely to become an on-going part of organizational experience. Transition may become a characteristic of effective organizational systems.

Every organization has a unique combination of characteristics that are experienced by members as organizational culture (Pacanowsky and O’Donnell-Trujillo, 1982). It has become clear that managers who understand and work within the organizational culture are in the best position to affect meaningfu1 change. In fact, Schein (1988) has suggested that the only thing of real importance managers as leaders do 'is to create and manage culture' (p. 2). Feldman (1988) puts the matter simply, explaining that organizational culture is the set of meanings created within the organization-norms, roles, plans, ideals, and ideas - that members use to 'make sense out of the flow of actions and events they experience' (p. 57).

Culture acts as a map that influences the way organizational members define events in the workplace; the process of learning an organization's culture involves learning the beliefs, assumptions, and expectations others have and how to act in terms of these particular values and norms (Schein, 1988; Bettinger, 1989; Bolman and Deal, 1984). The culture approach focuses attention on the processes by which the meanings of organizational events are produced and transmitted through communication (Deetz, 1982). Within this framework, reality is sociallycreated as employees observe their colleagues' responses to various events and interpret these experiences. Through communication-by participating in the process of creating shared meanings-organizational members come to understand the assumptions and experiences that subsequently guide their behavior (Putnam, 1982).

The transition process involves constant realignment of assumptions and expectations by all organizational members as they interpret and begin to make sense of their new tasks, role relationships, and work environments. This is often a long and complex adjustment process, 
since employees must gradually change their perceptions of 'the way things are' and ultimately reconsider their basic values and beliefs about the organization.

In service organizations, the customer's perceptions are also critical. Perhaps most significant are the public's expectations and assumptions about the nature of service. Controlling perceptions of service and its quality is neither easy nor straightforward. The symbol/cultural perspective draws attention to some of the most critical management concerns and reinforces, once again, the notion that the perception of reality is the reality:

...Whose perceptions should we focus upon to determine the reality? Should it be the perception of the hotel or of the company's management? Or should it be the guests' perception of the service...or should it be from the line employee's view... (Bromley, 1957, p. 4)

Another author notes, 'Good service has nothing to do with what the provider believes it is; it has only to do with what the customer believes is true' (Davidow and Uttal, 1989, p. 8-1). The intangibility of effective service has been a constant concern for those who seek to improve employee and organizational performance. Leaders gain valuable insight by viewing the customer/service employee relationship from the symbolic/cultural perspective and by considering the customer's perceptions of the organization's culture.

Organizational goals and service strategies must, in the long run, set all employees heading toward the customers' priorities (Albrecht and Zemke, 1985). Service initiatives at the organizational level often fail because the effort improves service in ways the customer doesn't really care about. The customer must be considered in determining and implementing organizational goals which guide all employees toward service-centered values. 
Often, the implementation of strategic plans requires a change in one or more cultural aspects. Organizational members must be prepared to follow new rules, address new issues, and adopt new ways of thinking about their work experiences. Hospitality leaders must understand how to introduce, implement, and monitor the plans they develop. New mission statements and expensive marketing campaigns can only succeed to the extent that managers also effectively communicate their visions to all employees and carefully manage the transition process.

\section{Culture and organizational change}

Hospitality managers must understand their organization's value structure in order to design culture-specific transition plans. It may be true, as Wilkins and Patterson (1985) propose, that because of specific cultural constraints some hospitality organizations simply cannot get from 'there to here' (p. 262). The next section examines the influence of values on the change process and describes three of the most significant barriers to planned change.

\section{Changing Values}

The organization's value orientation has a significant influence in guiding its performance and its response to change. Wilkins, Dyer and Gibb (19SS) point out that the values and beliefs of organizational members strongly influence whether and how communication strategies are implemented, even as the strategies themselves affect employees' perceptions of various cultural dimensions. When communication strategies are inconsistent with existing cultural values, planned change is almost certain to fail. Currently held beliefs inhibit change by (1) producing a strategic myopia where the significance of some events is missed or overlooked, and (2) affecting individuals' perceptions so that they respond to events in terms of their culture beliefs (Lorsch, 1986, pp. 99-100). 
Change efforts are certain to confront a degree of human resistance. While some members may simply have a low tolerance for change, others may feel that they will lose something of value. Still others, as mentioned earlier, misunderstand the change or do not understand why it is necessary (Kotter and Schlesinger, 1979). Many concerns, as Wilkins et al. (1988) point out, relate to the relationship between individuals and the organization when the balance that has been established is suddenly upset. Members ask, 'Why should I be a part of the whole and contribute to it?' (p. 524). This may be particularly true in an industry where high turnover and part-time employment is the norm, and where high percentages of the workforce see few if any long-term career opportunities.

Managers' values and beliefs have a major impact on the decisions they make and the strategic plans they choose. The relationship between corporate culture and strategic planning is reciprocal; while the culture affects how strategies are implemented and the impact they are likely to have, the organization's values influence the nature of the choices made and the strategies selected. Cultural values, then, have a direct impact on the degree and manner in which organizations adapt and respond to change (Stata, 1989; Fitzgerald, 1988).

Can planned management intervention change corporate cultures by changing the value system itself? Wiener (1988) believes that since values are largely evolutionary and emergent, the internalization of values involves a complex process that cannot be accomplished through formal decisions and organizational practices alone. As Fitzgerald (1988) notes, ‘... we have no theory to account for the process by which values are relinquished and replaced, either through the inner work of the person or some outside agency' (pp. 10-11). Organizations that have a well-established history and tradition, characteristic of many in the hospitality industry, find the process of changing underlying values particularly problematic (Zeira and Avedisian, 1989). 
Several other factors also have a significant impact on the hospitality industry. These barriers create additional challenges for those who manage the transition process.

\section{Barriers to planned change}

Although many factors make organizational transition difficult, the key barriers to change from the symbolic/culture perspective must include: (1) the customer as partial employee, (2) the increasingly diverse workforce, and (3) the rapid pace of innovation and subsequent uncertainty. Each of these aspects are discussed as they affect the implementation of strategic plans.

\section{Barrier one: the customer as partial employee.}

Complicating the change process in service industries is the fact that the customer him or herself often participates in the creation and delivery of the organization's primary productservice. The perceptions customers have of the organization are largely developed through their personal interactions with company representatives, particularly the customer service employee. Reliance on high levels of customer/provider interaction for service delivery poses a unique challenge both for hospitality managers and their service staff.

Since the customer participates in the service encounter, it is difficult for managers to plan or control service quality, particularly during high contact situations. In a sense, customers become 'partial employees', since they actually participate in the production of the service they receive. In high contact service systems, the customer affects the time of demand, the exact nature of the service, the length of the encounter, and the service quality itself. These factors lead to a high degree of uncertainty in day-to-day operations and make high contact service systems the most difficult to manage efficiently.

The success of any transaction not only depends upon the nature of the service and the specific tasks required, but also on the customer's communication skills, his or her motivation to 
ensure that the transaction goes smoothly, and individual personality characteristics. The customer/service provider relationship implies a set of mutual expectations regarding each parties' rights, privileges, and obligations. While some interactions have well-developed rules governing the actions of both participants, others are more ambiguous; the parties involved in the encounter must closely attend to the other's behavior in order to make appropriate choices. At the moment of service, the organization's representative can no longer be influenced by the company; the employee's skills and the behavior of the customer alone interact to produce the delivery of service (Worsfold, 1989).

In some instances, customers may be so naïve and their expectations so unclear that they are unable to determine exactly what 'good service' means. In other cases, the customer's expectations are precisely defined and changes in any aspect of the process are likely to have serious and often unpredictable consequences for the organization. Businesses that rely heavily on the customer's participation in the delivery of service-hotels, restaurants, health centers-are among the most challenging operations for strategic planners and others who are called upon to implement and manage organizational change.

\section{Barrier two: diverse workforce.}

Every employee comes to the organization with a set of expectations, predispositions, and personal skills that have been developed through previous observation or participation in similar encounters. Individuals who don't share the same sets of assumptions - whose background or culture is very different from that of the other organizational members-will experience difficulties both in adjusting to organizational requirements and in facilitating effective service encounters. The particular location of a property determines its primary labor pool; managers accustomed to employees who take pride in their professional conduct discover that other 
populations have very different attitudes, expectations, and levels of job commitment.

Motivating and training these workers becomes a complicated task.

The customer-service employee relationship is also affected by the diverse backgrounds of the customers themselves. When customers enter service encounters with low status and little credibility, they are often extended less discretion than others in similar situations and must work to establish themselves as legitimate recipients of the service (Mills and Morris, 1986). Teenagers who are ignored by service staff, the handicapped, or women who dine alone in restaurants, all are occasionally victims of this perceived relationship (Iles and Auluck, 1988). The diversity of the workforce itself further complicates these encounters; employees are challenged to provide service that meets the organization's standards regardless of their personal response to a customer.

As service organizations become increasingly multi-national and as the workforce becomes increasingly diverse, there will be a growing demand for organizational leaders who are sensitive to the needs of the minority members, and for service providers who understand the unique assumptions and values of their various publics. Women, people of color, the handicapped, and other minorities will likely play increasingly important roles in the service process, both as customers and as employees. Organizations undergoing transition must accommodate their minority members by adopting values that support the greater flexibility and adaptability needed to respond to these new responsibilities.

\section{Barrier three: rapid change and uncertainty.}

Cultures take time to develop. As organizations undergo transitions brought about both through strategic planning as well as through unplanned events, change must be perceived as a desirable and perhaps even permanent organizational reality. Employees who are unconvinced of 
the need for change or who misunderstand the organization's new goals communicate their uncertainty and confusion to guests and larger publics. Only when change itself becomes an accepted and valued norm will organizations anticipate and respond appropriately to shifts in both internal and external environments.

Even properties with long traditions are gradually moving toward automated systems to handle many of their information-processing needs. Routines that have been established and perpetuated over long periods of time are gradually giving way to more efficient and more sophisticated systems. Hospitality organizations cannot shut down while these changes are taking place, nor can they expect that these changes are permanent solutions. Customers as well as employees must be ready to constantly adapt to new and unexpected routines and rituals. Advanced technology and sophisticated information systems change the nature of interpersonal relationships, both among employees and between the customer and the service representative (More and Laird, 1983). What it 'means' to check in and out, take an order, or request information is dependent upon the balance between human contact and hardware; the introduction of automated systems affects expectations, assumptions, and beliefs about the nature of work and the quality of the service provided.

The hospitality industry is characterized by high levels of uncertainty in its operations and service encounters. When a bus arrives, a major disaster strikes, or the weather changes, hospitality organizations are expected to respond. Few other organizations experience the same high degree of continuous uncertainty. As we have seen, when there is a high degree of customer involvement in the service process and a correspondingly high degree of ambiguity in the tasks to be performed, the potential for disruption of the service process increases. Under these 
circumstances, both the customer and the employee are likely to experience frustration and stress.

Clearly, in an environment where some degree of uncertainty is the norm, planning may indeed be perceived as bothering about 'the best method to accomplish an accidental result' (Allaire and Firsirotu, 1989, p. 7). Service organizations must be designed to absorb uncertainties over which they cannot exert control. In light of these and other barriers to change, it becomes apparent that the organization's culture significantly influences its ability to move through the transition process. Managers who guide organizations through these changes while anticipating future shifts require special communication competencies. Organizational leaders depend upon such strategies as language techniques, information sharing, and effective listening to implement strategic plans within the framework of their organization's existing culture.

\section{Communication strategies to implement strategic change}

Strategic change requires a fundamental rethinking of the beliefs by which the organization defines and carries on its business (Lorsch, 1986). The role of managerial communication in implementing this change process cannot be overestimated (Bramson, 1989; Huseman, Alexander and Driver, 1980). As one author notes, 'Planning change is one thing, managing transitions another. And it's the transition that will foul up your well-planned change' (Bridges, 1985, p. 28).

It appears that there has been a shift from the management of human resources to the 'management of symbolic resources' (Bert, 1986, p. 557). Symbolic resources are the symbols and images that can be developed and utilized to guide corporate actions and events. As Tichy (1983) explains, the 'right stuff' for managers of the future, for the new transformational leaders, 
includes the ability to articulate new values and norms and then to 'use multiple change fevers' ranging from language techniques to appropriate channel selection to careful listening. Used effectively, these and other communication strategies move the organization toward desired goals. Several of these change levers appear to be particularly relevant to service managers who seek to implement their strategic plans.

\section{Language techniques: strategies for changing values}

In order for any meaningful change to occur, managers must develop a vision of their organization's future and implement strategies that will make that vision a reality (Hickman and Silva, 1984). Although values remain one of the most intangible and therefore elusive aspects of organizational life, culture leaders must search for communication strategies that will affect members' underlying values. Two approaches appear to have merit: (1) the use of ambiguity as a communication strategy and (2) stories and myths.

Eisenberg (1984) proposes a method he calls strategic ambiguity to promote 'unified diversity' (p. 232). He believes that ambiguity is especially powerful in changing environments, since ambiguous statements of core values can preserve a sense of continuity while allowing for both individual interpretations of events and gradual changes in interpretation over time. Ambiguity, then, is seen as desirable; hospitality leaders must infuse employees with values and purpose at a level of abstraction at which agreement can occur even among members of a highly diverse workforce.

Myths and stories that communicate an organization's culture are symbolic; values can be expressed through these vehicles because, again, such devices allow for multiple interpretations while at the same time promoting a sense of cohesiveness (McWhinney and Batista, 1988). 
Individuals believe that they understand and agree on the meaning, yet their specific interpretations of the story or myth may be quite personal and unique.

An example of how a myth can be used to reinforce service attitudes is expressed simply through a story the management of one hospitality industry tells its new employees. The story has become part of the cultural myths of that property, setting up a model for appropriate behavior. The story goes:

A guest was checking out of the Sunset Motel, chatting informally with a member of the front desk staff. The guest then went outside in front of the hotel to catch a cab. As the cab pulled away, the doorman noticed that the man had left one of his bags on the sidewalk. He immediately checked with the front desk, where the employee remembered that the man had said he was headed for a business appointment at a company in a nearby subdivision. The two employees looked up the address, and the doorman hailed another cab and headed out to return the guest's bag. (Lundberg, 1989)

The story's messages are clear: (1) take the time to know your guests personally, (2) take initiative, (3) work together, and (4) the service concept extends beyond the employee's job description. Stories and myths send important messages regarding organizational culture and individual behavior.

Since service is difficult to measure and to evaluate, these stories describe what effective service means within a particular context. Hospitality managers, in particular, must deal with employees who have low levels of motivation and modest salaries. These factors often make it difficult to develop a caring and competent staff. Effective managers rely on informal networks to strengthen the service culture. They use the myths and stories that circulate among employees to communicate important messages regarding quality and professional behavior. Quality, as 
Peters and Austin (1985) repeat, is not a technique; it's a matter of passion and pride-values that are instilled through the daily activities of organizational members. The values fostered through shared stories and myths can encourage collaboration and teamwork (Garsombke, 1988).

\section{Managers as boundary spanners}

Information sharing is a key management function; effective leaders rely on both formal and informal communication channels, orchestrating a process which funnels information from corporate executives down to line managers, who then interpret information in light of their smaller operating units. It becomes essential that all members understand where the company is headed. As leaders 'mobilize commitment to a new vision' (Spector, 1989, pp. 29-30), they must recognize the interrelationships among the organization's various components so that the impact of certain types of information on a particular department or division can be predicted and controlled.

As might be expected, the flatter and more flexible the organizational structure, the more quickly and freely information travels and the more responsive the organization is to change. When communication flows in all directions, when authority is decentralized, when job descriptions are general and there is a high level of participation in decision-making, organizational members readily respond to change efforts (Zeira and Avedisian, 1989). As John F. Welch, Jr, CEO of General Electric, noted in a recent interview, winning cultures are moving toward a 'boundaryless' company where barriers between functional areas evaporate (Fortune, $\mathrm{p}$. $30)$.

Information sharing in itself is a symbolic way of equalizing power, overcoming conflict, and building trust (Spector, 1989). The success of these efforts is heavily dependent upon the 
manager's style and philosophy. Few other organizations are as affected by the specific individuals who create and manage organizational culture as the service industry.

Unlike traditional mechanical models of information dissemination, the symbolic/cultural perspective views the sharing of meanings as a delicate process that requires sensitive and skilled communicators who must understand their partners' unique perceptions. Effective managers, therefore, play a key role in insuring that the messages travelling through the organization are accurately interpreted and understood. When these messages involve change, managers must ensure that employees are able to accurately interpret this information in terms of their own job requirements.

One of management's key roles, then, is to serve as boundary spanners or human links, translating expectations and rules to those below them while communicating lower level employee needs and concerns to upper level management. Managers not only link various organizational groups vertically, they also bridge differences in perceptions horizontally across functional areas as well. The symbolic/cultural approach to understanding organizational behavior provides insight into this process, since managers must constantly work to share meanings and understand the perceptions of those with different interests and backgrounds. A distinguishing feature of hospitality organizations is that the boundary spanning role must be performed by customer service employees as well as by managers, since it is the service employee who assumes responsibility for translating the organization's rules to the customer while simultaneously interpreting and responding to the customer's expectations and demands. When customer role readiness is low or when customers are poorly prepared for the encounter, the process of role negotiation and boundary spanning becomes particularly difficult. Because the service employee represents the organization so directly, managers must influence those who 
interact with customers so that service values and organizational priorities are realized. During transition periods, the service representative's behavior is key to influencing the customer's perceptions of service quality and in establishing the organization's new image.

Boundary spanners must be able to see situations and events as they appear to dishwashers as well as to the director of food and beverage; they must understand the perceptions of the reservations manager as well as those of the employees in the marketing department. Boundary spanners need to listen well; in order to perform effectively they must remain objective in their assessment of the problems that arise and communicate empathy and understanding to all parties involved. These communication skills are vital for managers who serve as leaders in implementing planned change.

\section{Model effective listening behaviors}

Managers influence culture and encourage shared organizational values through personal example and deliberate role modeling. Schein (1988) repeatedly reminds managers that the organization's values and assumptions are 'manifested first in what leaders demonstrate, not in what is written down or inferred' (p. 237). By modeling desirable communication behaviors, hospitality leaders demonstrate appropriate responses to the critical incidents that arise during the transition process (Frank and Brownell, 19S9). These managers vividly show employees how a successful member interacts and responds to the variety of unpredictable situations that accompany organizational transitions.

During transition periods, all employees must eventually learn new attitudes and behaviors as well as adapt to changing circumstances (deGeus, 19SS). In such environments, the skills of active listening are particularly important. Active listeners demonstrate objectivity, open-mindedness, and flexibility. Listening also encourages the supportive climate essential to 
the development of interpersonal trust. By demonstrating active listening behaviors on a daily basis, hospitality managers send a powerful message to their colleagues.

Since managers serve as information links, their ability to listen objectively and to convey messages accurately is prerequisite to smooth transitions. As the workforce becomes increasingly diverse, the skills required to ensure accurate understanding become even more essential. Managers must bridge differences among individuals whose perceptions and viewpoints are dissimilar. The quality of decision-making is also affected by managers' listening skills. In processing and disseminating large quantities of information, managers must accurately assess the relative importance various messages have to different divisions or departments. Leaders must listen well before they can predict the impact changes will have on organizational components.

Managers further encourage information sharing by developing skills in empathic listening. This means that managers maintain an open mind, withhold their opinions, and project a willingness to listen even to those who hold unpopular views. These behaviors, too, encourage interpersonal trust and create a climate in which members increase their information sharing activities. As organizational members receive and process information, they adjust their perceptions to the new or changing cultural dimensions. Unless organizational members are able to adapt to new circumstances, they risk operating under outdated assumptions and unrealistic expectations. When managers listen to employees' feelings as well as their words, they quickly recognize signs of resistance to new ideas and can take steps to reduce such barriers to change.

Employees who model effective listening behaviors not only adapt more quickly to the changing workplace, but also find that their relationships with both co-workers and customers 
improve. When organizational members listen well, misunderstandings are reduced, goals are shared, and employees perceive the workplace as more supportive and satisfying.

Managers must be ready to influence organizational culture through their language and through the myths and stories they circulate about what is valued in the organization's culture. Only by sharing information in all directions can managers develop support for their new ideas and plans. Successful change efforts require that the perceptions of all organizational members be understood and addressed. The attitudes, beliefs, and assumptions that guide each specific group must be taken into account during the change process. This task requires managers who are skilled listeners, individuals who are able to create shared meanings among all who must support the change.

\section{Conclusion}

The effective implementation of strategic plans requires managers to understand the cultural/symbolic nature of organizations and to develop a comprehensive communication strategy that will shape employee's perceptions and direct them toward values that support the organization's mission (Bramson, 1989). To enlist employee and customer commitment, and to move organizational members toward these new goals, managers must plan their communication strategies as carefully as they design their mission statement. It is clear, as Kanter (1983) and others repeat: 'Change masters deal in symbols and visions and shared understandings' (p. 305).

The service industry needs to look carefully at how it can prepare managers to guide their organizations through the 1990's and into the next century. The symbolic/culture approach appears to provide a useful perspective, particularly as it accounts for the role of the manager in facilitating the change process. Since there is some indication that hospitality organizations have 
similar cultural aspects (Woods. 1989), insights gained by one organization are likely to have application to others as well.

As leaders in a society now dominated by service workers, managers must encourage and facilitate learning environments within their organizations. They must implement communication strategies that will influence the values, assumptions, and ultimately the daily behavior of organizational members and customers alike.

One 'given' in any organization's future is that changes will occur... The ability to manage transition is a necessity... But few organizations have a transition-sensitive culture and few leaders and managers have any training in transition management. With the frequency of organizational change, that is a dangerous combination today. Tomorrow it will be disastrous. (Bridges, 1985, p. 32)

Hospitality managers who plan for the future must equip themselves with the communication skills needed to implement and manage the change process. In an industry characterized by uncertainty and high levels of customer contact, it is essential that managers design strategies to influence employee and customer perceptions and apply communication practices that reduce resistance to new plans and facilitate what may well be continual organizational change. 


\section{References}

Albrecht, K. and Zemke, R. (1985) Service America-Doing Business in the New Economy. Dow-Jones Irwin, Homewood, IL.

Allaire, Y. and Firsirotu. M.E. (1989) Coping with strategic uncertainty. Sloan Management Review 30, 7-16.

Bean, A., Ordowich, C. and Westley, W. (1985-1986) Including the supervisor in employee involvement efforts. National Productivity Review 5, 64-77.

Belasco, J.A. (1989) What went wrong? Executive Excellence 6, 13-14.

Berg, P.O. (1986) Symbolic management of human resources. Human Resource Management $25,557-580$.

Bettinger, C. (1989) Use corporate culture to trigger high performance. Journal of Business Strategy 10, 38-42.

Bolman, L. and Deal, T. (1984) Modern Approaches to Understanding and Managing Organizations. Jossey-Bass, San Francisco.

Bonoma, T. V. and Lawler. J. C. (1989) Chutes and ladders: Growing the general manager. Sloan Management Review (Spring), 27-37.

Bramlette, C. A. Jr (1981) Free to change. Training and Development Journal 38, 32-40.

Bramson, R. N. (1989) The corporate wonderland. Personnel Administrator 34, 72-79.

Bridges, W. (19S5) How to manage organizational transition. Training: The Magazine of HumanResources Development 22, 28-33.

Bromley, S. (1987) The specialist: Coming soon to your local hotel. FIU Hospitality Review 5, 14.

Bunning, R. L. (1984) Coping with large scale change. Hospital Forum 27, 71-75. 
Clark, R. S. (1988) Gearing up for a strategic change. CA Magazine 121, 24-35.

Davidow, W. H. and Uttal. B. (1989) Service companies: Focus or falter. Harvard Business Review 4, 77-85.

Deetz, S. (1982) Critical interpretive research in organizational communication. Western Journal of Speech Communication 16, 131-119.

Deetz, S. (1985) Critical-cultural research: New sensibilities and old realities. Journal of Management 11, 121-136.

deGeus, A. P. (1988) Planning as learning. Harvard Business Review (March-April), 70-74.

Donnelly, R.M. (19) The interrelationship of planning with corporate culture in the creation of shared values. Managerial Planning (May/June), 8-12.

Eisenberg, E. M. (1984) Ambiguity as strategy in organizational communication. Communication Monographs 51, 227-242.

Feldman, S. P. (1988) How organizational culture can affect innovation. Organizational Dynamics (Summer), 57-48.

Fitzgerald, T. H. (1988) Can change in organizational culture really be managed? Organizational Dynamics (Autumn), 4-15.

Frank, A. and Brownell, J. (1989) Organizational Communication and Behavior: Communicating to Improve Performance $(2+2=5)$. Holt. Rinehart \& Winston, New York.

Garsombke, D. J. (1988) Organizational culture dons the mantle of militarism. Organizational Dynamics (Summer), 46-56.

Grant, J. (1958) Women as managers: What they can offer to organizations. Organizational Dynamics 16, 56-63. 
Greenbaum, H., Holden, E. and Spataro, L. (1983) Organizational structure and communications process: A study of change. Group and Organization Studies 8, 61-82.

Greene, J. (1985) Change management. Modern Healthcare 18, 20-31.

Harris, P. R. (1989) Developing the learning manager. Journal of Managerial Psychology 1,1721.

Hickman. C. R. and Silva, M. A. (1984) Creating excellence: Managing Corporate Culture. Strategy and Change in the New Age. New American Library, New York.

Hunsaker, P. (1982) Strategies for organizational change: The role of the inside change agent. Personnel 59, 18-28.

Hunsucker, J. L. and Loos, D. (1989) Transition management: An analysis of strategic considerations for effective implementation. Engineering Management International 5, $167-178$.

Huseman, R. C., Alexander, E. R. III and Driver, R. W. (1980) Planning for organizational change: The role of communication. Managerial Planning 28, 32-36.

Iles, P. and Auluck. R. (1988) Managing equal opportunity through strategic organization development. Leadership and Organization Development Journal 9, 3-10.

Jacobs, D. (1987) Management audits as instruments of change. International Management 42, 54.

Kanter, R. M. (1983) The Change Masters: Innovation for Productivity in the American Corporation. Simon \& Schuster, New York.

Kanter, R. M. (1987) Managing traumatic change: Avoiding the unlucky 13. Management Review 76, 23-24.

Kern, R. (1988) When the dust settles. Personnel Administrator 33, 81-83. 
Kotter, J. P. and Schlesinger, L. A. (1979) Choosing strategies for change. Harvard Business Review 57, 106-1 14.

Lorsch, J. W. (1986) Managing culture: The invisible barrier to strategic change. California Management Review 27, 95-109.

Lowy, A., Kelleher, D. and Finestone, P. (1986) Management learning: Beyond program design. Training and Development Journal 40, 34-37.

Lundberg, C. (1985) On the feasibility of cultural interventions in organizations. In, Organizational Culture P. J. Frost, L. F. Moore, M. R. Louis, C. Lundberg and J. Martin (eds), pp. 169-185. Sage, Beverly Hills, CA.

McEwen, N. et al. (1988) Managing organizational change-a strategic approach. Long Range Planning 21, 71-78.

McLaughlin, T. (1985) Six keys to quality. Quality Progress 18, 77-79.

McWhinney, W. and Batista, J. (1988) How remythologizing can revitalize organizations. Organizational Dynamics (Autumn), 46-58.

Meares, L. B. (1986) A model for changing organizational culture. Personnel 63, 38-43.

Mills, P. K. and Margulies. N. (1980) Toward a core typology of service organizations. Academy of Management Review 5, 255-266.

Mills, P. K. and Morris, J. H. (1986) Clients as 'partial' employees of service organizations: Role development in client participation. Academy of Management Review 11, 726-735.

Moth, M. and Huff, A. (1983) Power enactment through language and ritual. Journal of Business Research 11, 293-316.

More, E. and Laird, R. K. (1983) Modern technology and organizational communication implications for management. Journal of Information Science 7, 169-183. 
Ouchi, W. G. (1981) Theory Z. Addison-Wesley, Reading, MA.

Pacanowsky, M. E. and O’Donnell-Trujillo, N. (1982) Communication and organizational cultures. The Western Journal of Speech Communication 46, 115-130.

Peters, T. (1988) Managing in the '90s: Creating the fleet-footed organization. Industry Week $236,35-39$.

Peters, T. (1989) Operating principle 1: Listen, understand, and respond to customers. In, The Service Edge: 101 Companies that Profit from Customer Cure Ron Zemke and Dick Schaef (eds), pp. 29-35. NLA Books, New York.

Peters, T. and Austin, N. (1985) A Passion for Excellence: The Leadership Difference. Random House, New York.

Price, C. N. (1988) Organization change in personnel management. Leadership and Organization Development Journal 9, iii-vi.

Putnam, L. L. (1982) Paradigms for organizational communication research: An overview and synthesis. The Western Journal of Speech Communication 46, 192-206.

Rees. A., West, M. and Brooks-Rooney, A. (1988) Bringing in the experts: Self-help in a learning organization. Leadership and Organization Development Journal 9. vi-viii.

Ryan. M.G.. Baldwin. S. and Douglas, W. (1980) Communication strategies for organizational change. Optimum 7, 47-56.

Schein, E. H. (1988) Organizational socialization and the profession of management. Sloan Management Review 30, 53-65.

Schein, V. (1977) Political strategies for implementing organizational change. Group and Organization Studies 2, 42-48.

Schneider, B. (1980) The service organization: Climate is crucial. Organizational Dynamics. 
Shamir. B. (1978) Between bureaucracy and hospitality—some organizational characteristics of hotels. The Journal of Management Studies (October), 285-307.

Shanks, D. C. (19) The role of leadership in strategy development. Journal of Business Strategy $10,32-36$.

Smircich, L. (1983) Concepts of culture and organizational analysis. Administrative Science Quarterly 28, 339-358.

Spector, B.A. (1989) From bogged down to fired up: Inspiring organizational change. Sloan Management Review 30, 29-34.

Stata, R. (1989) Organizational learning-the key to management innovation. Sloan Management Review 30, 63-74.

Tichy, N. M. (1953) Managing Strategic Change: Technical, Political and Cultural Dynamics. John Wiley, New York.

Tichy, N. and Ulrich, D. (1984) Revitalizing organizations: The leadership role. In, Managing Organizational Transitions J. R. Kimberly and R.E. Quinn (eds). Richard D. Irivin, Homewood. IL.

Umbreit, W. T. and Eder. R. W. (1987) Linking hotel manager behavior with outcome measures of effectiveness. International Journal of Hospitality Management 6, 139-147.

Wiener. Y. (1988) Forms of value systems: A focus on organizational effectiveness and cultural change and maintenance. Academy of Management Review 13, 534-545.

Wilkins, A.L., Dyer, W. and Gibb, Jr (1988) Toward culturally sensitive theories of culture change. Academy of Management Review 13, 522-533. 
Wilkins, A. L. and Patterson. K. J. (1985) You can't get there from here. In, Gaining Control of the Corporate Culture R. Kilmann, M. J. Saxton. R. Serpa and associates (eds), pp. 262291. Jossey-Bass. San Francisco.

Wiio, O.A. (1988) Organizational communication: Contingent views. In, Handbook of Organizational Communication G.M. Goldhaber and G.A. Barnett (eds). pp. 95-100. Ablex Publishing. Norwood, NJ.

Woods, R. H. (1989) More alike than different: The culture of the restaurant industry. The Cornell Hotel and Restaurant Administration Quarterly (August), 82-97.

Worsfold, P. (1989) A personality profile of the hotel manager. International Journal of Hospitality Management 8, 51-62.

Young. J. and Smith, B. (1988) Organizational change and the HR profession. Personnel 65, 44. Zeira, Y. and Avedisian, J. (1989) Organizational planned change: Assessing the chances for success. Organizational Dynamics (Spring), 31-45. 


\section{About the Author}

Judi Brownell is an associate professor in the School of Hotel Administration at Cornell University where she teaches graduate and undergraduate courses in managerial and organizational communication. She is an active participant in the School's executive education programs, and has developed training programs for a wide variety of organizations on such topics as: customer service, listening to guests, managing conflict, dealing with difficult employees, developing and delivering effective presentations, and written communication.

Professor Brownell is co-author of Organizational Communication and Behavior: Communicating to Improve Performance (1989), and author of Building Active Listening Skills (1986). Several of her articles have appeared in the Cornell Hotel and Restaurant Administration Quarterly, as well as numerous other professional journals. Currently she is writing two invited chapters, one on Listening in Service Organizations, the other on Gender and Communication in the Hospitality Industry.

Professional association offices held include: President, Southern tier Chapter of the American Society for Training and Development (1985); Vice President Elect, New York State Speech Communication Association (1979); and Secretary (1988) and chair of the public relations committee (1989), International Listening Association. In 1988, she won the International Listening Association's research award for her work on employees' perceptions of managerial listening behavior. 